CS 2018.01.01.2

Bionatura Conference Series Vol 1. No 1. 2018

Publicación del IV CONGRESO INTERNACIONAL DE BIOTECNOLOGÍA Y

BIODIVERSIDAD IV CIBB Y XV FORO INTERNACIONAL BANANERO

INVESTIGATION / RESEARCH

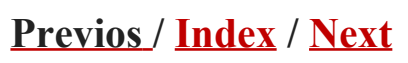

\title{
Evaluación del almidón de papa (Solanum tuberosum) en la obtención de bioplástico
}

Employment of the potato (Solanum tuberosum) type fourth category for the obtaining of bioempacks.

Acosta, $J^{1}$, Gomajoa, H1, Benavides, $Y^{2}$, Charfuelan, $A^{2}$, Valenzuela, $F^{2}$ Disponible en: http://dx.doi.org/10.21931/RB/CS/2018.01.01.2

\section{RESUMEN}

Los bioplásticos a partir de almidón, son productos innovadores con un gran potencial de desarrollo y altamente amigables con el medio ambiente; en tal sentido, se evaluó el almidón extraído de cinco variedades de papa categoría richi (Superior (S), ICA Capiro (IC), Betina (B), Parda Pastusa (PP) y Criolla (C)) para la obtención de bioplásticos. Para lo anterior, se extrajo el almidón por el método de decantación natural, se determinó sus propiedades fisicoquímicas como temperatura de gelatinización (Tg), índice de absorbancia (IA), índice de solubilidad (IS), poder de hinchamiento (PDH), proteína, amilosa y amilopectina teniendo en cuenta la norma ISO 6647. Los resultados de cada variedad se evaluaron con una matriz de priorización, posteriormente, se elaboró el bioplástico siguiendo la metodología realizada por (Meza, 2016) y validado con un diseño unifactorial, donde se evalúa la incidencia del porcentaje de almidón $(3,6,8 \%)$ en la mezcla, como variables de respuesta resistencia y calibre con 2 réplicas. Los resultados indican que la variedad (B) tiene las mejores características con $64,125^{\circ} \mathrm{C}$ para $\mathrm{Tg}$, para IA $3.130 \mathrm{~g}$ gel/g, IS $18,75 \mathrm{~g} / \mathrm{ml}$, PDH 4.03 , proteína $0.341 \%$, amilosa $20,751 \mathrm{mg} / \mathrm{L}$ y amilopectina $79,249 \mathrm{mg} / \mathrm{L}$. El bioplástico obtenido de esta variedad presentó características de resistencia de $25.35 \mathrm{MPa}$ y calibre $0.17 \mathrm{~mm}$ obteniendo las mejores características 
mecánicas del bioplástico. Se concluye que el almidón de papa de categoría richi tiene alta potencialidad para la generación de bioplástico.

Palabras clave: Almidón; bioempaques; plastificantes; papa de cuarta categoría; resistencia; biodegradabilidad.

\section{ABSTRACT}

The bioplastic products from starch, are innovative products with great potential for development and highly friendly with the environment; In this regard, the starch extracted from five potato varieties richi category (Superior (S), ICA Capiro (IC), Betina (B), Parda Pastusa (PP) and Criolla (C)) was evaluated to obtain bioplastics. For this, the starch was extracted by the natural decantation method, its physicochemical properties were determined as gelatinization temperature $(\mathrm{Tg})$, absorbance index (IA), solubility index (IS), swelling power (PDH), protein, amylose, and amylopectin taking into account ISO 6647. The results of each variety are evaluated with a prioritization matrix, subsequently, the bioplastic is elaborated following the function performed by (Meza, 2016) and validated with a unifactorial design, where Evaluate the incidence of $\%$ starch $(3,6,8 \%)$ in the mixture, as resistance and caliber response variables with 2 responses. The results indicate that variety B has the best characteristics with $64,125^{\circ} \mathrm{C}$ for Tg, for AI 3,130 g gel / g, IS $18.75 \mathrm{~g} / \mathrm{ml}, \mathrm{PDH} 4,03$, protein $0.341 \%$, amylose $20,751 \mathrm{mg} / \mathrm{L}$ and amylopectin 79,249 $\mathrm{mg} / \mathrm{L}$. The bioplastic obtained from this variety has strength characteristics of $25.35 \mathrm{MPa}$ and caliber $0.17 \mathrm{~mm}$ obtaining the best mechanical characteristics of the bioplastic. It is concluded that the starch of the potato of the category has the high potential for the generation of bioplastic.

Keywords: Starch; bio-packaging; plasticizers; fourth category potato.

\section{INTRODUCCIÓN}

El plástico y sus derivados provenientes de fuentes no renovables como el petróleo, son productos de gran utilidad en la industria alimentaria, farmacéutica, cosmética, etc. Sin embargo, este uso se ha incrementado de forma acelerada, generando 8.300 millones de toneladas anuales de residuos plásticos que se acumulan en el medio de los cuales el 79\% se encuentran en vertederos o en el entorno natural [1]. El problema radica en el uso que se le da, a la forma como es desechado luego de ser utilizado, un ejemplo claro es el caso de las bolsas plásticas usadas en los supermercados. Se calcula, para fabricar una bolsa plástica, se gasta un tiempo aproximadamente de cinco segundos, el tiempo de utilización del cliente es de 30 a 60 minutos y el tiempo de descomposición supera los 400 años, provocando una alta contaminación en afluentes de agua, causando muerte en las especies de la 
fauna marina, en el suelo no permite el crecimiento de nueva vegetación, afectando el ecosistema y en el aire, la incineración produce gases tóxicos que afecta la salud del ser humano, por ende ha aumentado las regulaciones medioambientales promoviendo el desarrollo de nuevos alternativas para la elaboración de materiales y productos que sustituyan los polímeros por bioplástico, cuyas características son mejor degradación, elaborados de fuentes renovables independientes de los combustibles fósiles y reducen el impacto negativo producido por el uso indiscriminado de las bolsas tradicionales [2].

En el anterior contexto, se destaca que una de las fuentes de producción de biomasa actualmente son los residuos de cosecha y subproductos vegetales, que para este estudio se enfoca a los generados en la producción de papa, dentro de los cuales el municipio de Cumbal, situado al sur occidente del departamento de Nariño tiene mucha incidencia, ya que su producción es netamente agropecuaria, cultivando en el año 2017 aproximadamente una área de 1.216 ha con una producción de 14.592 ton de papa [3]. Los agricultores después de terminar la cosecha, clasifican la papa según su tamaño de acuerdo con la norma NTC 341 en cuatro categorías: primera (cero), segunda (gruesa), tercera (pareja) y cuarta (richie o muro). Para su comercialización se tiene en cuenta que el producto esté en las mejores condiciones y de buena calidad [4]. La papa de cuarta categoría es considerada no comercial por su tamaño inferior a $3 \mathrm{~cm}$, en promedio el $9 \%$ de la producción de papa corresponde a este tipo, la cual es desechada o vendida a bajos precios para alimentación animal [5]; por ende, no se realiza ningún procesamiento o tratamiento, lo que genera pérdidas para los productores y contaminación ambiental. Además de esto originan desperdicios orgánicos que pueden ser aprovechados como biomasa, ya que la papa cuarta de categoría tiene $18 \%$ de contenido de almidón [5], que puede ser utilizada como materia prima para elaboración de diferentes productos.

Por tal razón, se plantea desarrollar un estudio de obtención de bioplástico a partir de almidón de papa, con el fin de aprovechar la papa de cuarta categoría, buscando nuevas alternativas eficientes para mejorar la economía de los agricultores del municipio de Cumbal. El sector del empaque a nivel regional también se vería beneficiado al encontrar disponibilidad en el mercado con productos biodegradables amigables con el medio ambiente reduciendo el índice de contaminación provocada por la alta demanda de plásticos convencional.

\section{MATERIALES Y MÉTODOS}

\section{Obtención de la Materia Prima}

La materia prima papa de cuarta categoría se obtuvo del municipio de Cumbal 
departamento de Nariño Colombia. La selección se realizó mediante el método de cuarteo, se dividió $50 \mathrm{~kg}$ de papa en 4 muestras, de cada muestra se escogió al azar 2,5 g de papa aleatoriamente, con total de $1000 \mathrm{~g}$ para cada variedad, posteriormente se realizó una clasificación descartando papa en estado de putrefacción, esta se transportó a las instalaciones del laboratorio Alvernia, Universidad Mariana.

\section{Caracterización de la papa de cuarta categoría.}

\section{Humedad.}

Se utilizó el método seco en termobalanza, en el cual se pesó 1 gramo de muestra de papa y se depositó en los platillos de la balanza de humedad (Ohaus), a una Temperatura de $110^{\circ} \mathrm{C}$, hasta que la muestra presente un peso constante [6]. El porcentaje de humedad lo genero el equipo mediante la diferencia de peso.

\section{Extracción del almidón}

Se realizó un lavado y reducción de tamaño aproximadamente $2 \mathrm{~mm}$, en una licuadora industrial (Exhibir). Para separar la fibra de la solución, se utilizó un tamiz (Alphalabs) No. 100 y se dejó decantar por 2 horas. Luego se secó el almidón, en un secador de bandejas (Fiq) a una $\mathrm{T}$ de aire de $30-35^{\circ} \mathrm{C}$, velocidad de $7,5 \mathrm{~m} / \mathrm{s}$ y una longitud transversal de $60 \mathrm{~cm}^{2}$ por $6 \mathrm{~h}$. A continuación, se realizó un tamizado con el fin de obtener un almidón homogéneo de un tamaño de $500 \mu \mathrm{m}$ se utilizó un tamiz eléctrico (Alphalabs).

\section{Caracterización del almidón de papa de cuarta categoría.}

\section{Humedad de almidón}

Se utilizó el método seco en termobalanza, en el cual se pesó 1 gramo de muestra de papa y se depositó en los platillos de la balanza de humedad (Ohaus), a una Temperatura de $110^{\circ} \mathrm{C}$, hasta que la muestra presente un peso constante [6]. El porcentaje de humedad lo genero el equipo mediante la diferencia de peso.

\section{Temperatura de gelatinización del almidón.}

Se pesó $10 \mathrm{~g}$ de almidón y se disolvió en $100 \mathrm{ml}$ de agua. Se llevó a calentamiento a una $\mathrm{T}$ de $85^{\circ} \mathrm{C}$, hasta obtener la formación de una pasta y la temperatura permanezca estable unos segundos, con un termómetro se tomó la temperatura de la solución [7]. 


\section{Densidad del almidón.}

Se depositó una muestra de almidón en una probeta de $50 \mathrm{ml}$, esta se llenó con almidón hasta un volumen de $25 \mathrm{ml}$, se realizó una nivelación, golpeteando manualmente la probeta. Finalmente se pesó la probeta en una balanza (Lexus) y se registró el volumen.

\section{Amilosa y amilopectina.}

Se determinó por el método colorimétrico, se depositó 20 gramos de almidón y se realizó la dispersión en medio acuoso, seguida de una gelatinización y reacción de los gránulos de almidón con yodo, posteriormente se midió por el método calorimétrico el complejo yodo-amilosa a una longitud de onda de $620 \mathrm{~nm}$ [8].

\section{Índices de absorción de agua, solubilidad y poder de hinchamiento.}

Se realizó mediante centrifugación a $900 \mathrm{RPM}$ por 30 min (Delca DM-0412) se pesó tubos secos a una temperatura de $60^{\circ} \mathrm{C}$. Se tomó $1,25 \mathrm{~g}$ de almidón con $30 \mathrm{ml}$ de agua destilada precalentada, se dejó la muestra en baño maría por 30 minutos. Posteriormente, se tomó $10 \mathrm{ml}$ del sobrenadante en un vaso de precipitados de 50 $\mathrm{ml}$, luego se secó la muestra en un horno digital de precisión (PINZUAR) a una temperatura de $70{ }^{\circ} \mathrm{C}$ por $24 \mathrm{~h}$. Luego se pesó el tubo de centrífuga con el gel y el vaso de precipitados con los insolubles. [9]

Se calculó mediante las siguientes formulas:

$$
\begin{gathered}
\text { Índice de absorción de agua }=\frac{\text { Peso del gel }(g)}{\text { Peso muestra }(g) b s} . \\
\text { ÍS en agua }=\frac{\text { Peso solubles }(g) \times V \times 10}{(\text { Peso muestra }(g) b s)}(2) \\
(P H)=\frac{\text { Peso del gel }(g)}{(\text { Peso muestra }(g) b s-\text { Peso solubles }(g))}
\end{gathered}
$$

\section{Nitrógeno (N) total y proteína cruda.}

Se realizó con el método de Kjeldahl, que transforma el N presente en las proteínas a sulfato de amonio por medio de la digestión con ácido sulfúrico en ebullición, Se enfrió la muestra residual y se adicionó $\mathrm{Na}(\mathrm{OH})$, luego se destiló el 
desprendimiento del amonio para ser titulado con ácido clorhídrico [10].

El cálculo del nitrógeno total de determinó mediante la siguiente fórmula:

$$
N T(\%)=\frac{((A G M-A G B) \times 1.4 \times N H C l)}{(\text { Peso muestra }(g))}
$$

AGM: ml ácido gastado en muestra

$A G B: m l$ ácido gastado en blanco

NHCl: Normalidad del ácido clorhídrico

$$
\text { Proteína cruda }(\%)=N T(\%) \times 6.25(5)
$$

\section{Elaboración de bioempaques}

Se realizó mediante un diseño experimental unifactorial, con el software estadístico STAGRAFICS CENTURION XV.II, donde se evaluó la incidencia de la valoración del porcentaje de almidón (3, 6 y 8\%) en la mezcla, como variables de respuesta la resistencia y calibre con dos réplicas. En la elaboración del bioplástico se adicionaron plastificantes Glicerina y Agua, como también un modificador químico ácido acético al $5 \%$, a una temperatura de $70{ }^{\circ} \mathrm{C}$ y una agitación constante; la

\begin{tabular}{|c|c|c|c|}
\hline \multicolumn{4}{|c|}{ Diseño experimental unifactorial } \\
\hline & \multicolumn{2}{|c|}{ Variables de respuesta } & Variables fijas \\
\hline $3 \%$ & \multirow{3}{*}{$\begin{array}{l}\text { Resistencia } \\
\mathrm{MPa}\end{array}$} & \multirow{3}{*}{$\begin{array}{l}\text { Calibre } \\
\mathrm{mm}\end{array}$} & Agua (ml) \\
\hline $6 \%$ & & & $\begin{array}{l}\text { Ácido acético } \\
\text { (ml) }\end{array}$ \\
\hline $8 \%$ & & & Glicerina (ml) \\
\hline
\end{tabular}
descripción del diseño se presenta en la tabla 1.

Tabla 1. Diseño Experimental

\section{Proceso de moldeado del material bioplástico.}

En el mezclado se colocó en un molde tipo bandeja la solución liquida caliente de bioplástico y se deja secar a una $\mathrm{T}$ de $25^{\circ} \mathrm{C}$ por $72 \mathrm{~h}$. Luego de obtener el material 
se procede a realizar el diseño de bioempaques.

\section{Determinación de las características fisicoquímicas del bioplástico}

\section{Porcentaje de Humedad del bioempaque.}

Se utilizó el método seco en termo balanza, en el cual se pesó 1 gramo de muestra de papa y se depositó en los platillos de la balanza de humedad (Ohaus), a una $\mathrm{T}$ de $110^{\circ} \mathrm{C}$, hasta que la muestra presente un peso constante [6]. El porcentaje de humedad lo genero el equipo mediante la diferencia de peso.

Determinación de las características mecánicas del bioplástico.

\section{Espesor del bioplástico.}

Se realizó con un micrómetro (Vertex), de resolución $0,01 \mathrm{ml}$, se utilizó probetas 12 $\mathrm{cm}$ de largo y 2,5 cm de ancho [11]. La medición se realizó en diferentes puntos de la probeta.

\section{Resistencia de bioplástico.}

Se evaluó de acuerdo a la norma ASTM D638-10, en la máquina Universal (Dirimpex). En la cual se determinó el esfuerzo en la rotura y el módulo elástico en las muestras de bioplástico. Se utilizó una probeta de $12 \mathrm{~cm}$ de largo y 2,5 cm de ancho, donde ejerce una fuerza hasta la ruptura.

La resistencia se calculó mediante la siguiente fórmula:

$$
\text { Resistencia }=\frac{F N R M(N)}{A S T\left(m^{2}\right)}
$$

Donde:

FNRM = Fuerza necesaria para romper la muestra AST = Área de la sección transversal 


\section{Determinación de la biodegradabilidad del bioplástico.}

Se evaluó mediante el método gravimétrico, las láminas de bioplástico con medidas de $5 \mathrm{~cm} \times 5 \mathrm{~cm}$ se exponen a condiciones aeróbicos por 15 días a una profundidad de $10 \mathrm{~cm}$, la pérdida de peso se midió después del tiempo establecido [12].

Se utilizó la siguiente fórmula.

$$
\% \text { Perdida de peso }=\frac{P I S-P F P}{P F P} * 100
$$

Donde:

$P I S=$ Peso inicial seco

$P F P=$ peso final de película

\section{RESULTADOS Y DISCUSIÓN}

\section{Características fisicoquímicas de cinco variedades de papa.}

Los resultados de las pruebas fisicoquímicas realizadas a los diferentes almidones se presentan en la siguiente tabla 2 :

\begin{tabular}{|ccccccc|}
\hline $\begin{array}{c}\text { Tipo de } \\
\text { Almidón }\end{array}$ & $\begin{array}{c}\% \\
\text { Humedad }\end{array}$ & $\begin{array}{c}\% \\
\text { Ceniza }\end{array}$ & $\begin{array}{c}\% \\
\text { Proteína }\end{array}$ & $\begin{array}{c}\% \\
\text { Amilopectina }\end{array}$ & $\begin{array}{c}\% \\
\text { Amilosa }\end{array}$ & $\begin{array}{c}\% \\
\text { Rendimiento }\end{array}$ \\
$\begin{array}{c}\text { Superior (AS) } \\
20.003^{\mathrm{b}}\end{array}$ & $0,171^{\mathrm{a}}$ & $0,753^{\mathrm{b}}$ & $84.268^{\mathrm{b}}$ & $15.732^{\mathrm{a}}$ & 12,9 \\
$\begin{array}{c}\text { Criolla (AC) } \\
\text { ICA-Capiro }\end{array}$ & $16.927^{\mathrm{a}}$ & $0,192^{\mathrm{a}}$ & $0,696^{\mathrm{b}}$ & $74.519^{\mathrm{a}}$ & $25.481^{\mathrm{b}}$ & 9,69 \\
$\quad 18.180^{\mathrm{a}}$ & $0,417^{\mathrm{a}}$ & $0,673^{\mathrm{b}}$ & $78.848^{\mathrm{ab}}$ & $21.152^{\mathrm{ab}}$ & 10,36 \\
$\begin{array}{c}\text { Parda (AP) } \\
\text { Betina (AB) }\end{array}$ & $20.050^{\mathrm{b}}$ & $0.5033^{\mathrm{a}}$ & $0,383^{\mathrm{a}}$ & $75.951^{\mathrm{a}}$ & $24.049^{\mathrm{b}}$ & 9,85 \\
\hline
\end{tabular}

Tabla 2. Características fisicoquímicas de cinco variedades de papa.

Porcentaje de Humedad: Las medias de los almidones con respecto a la variable humedad, presentan variaciones significativas, con un valor de $\mathrm{p}$ igual a $0(\mathrm{p}<\alpha)$ y un nivel de confianza del $95 \%$, por lo tanto, se conformaron dos grupos los cuales difieren entre sí, el primer grupo conformado por AC y AIC, el otro grupo integrado por AS, AC Y AB, ver figura 1. 


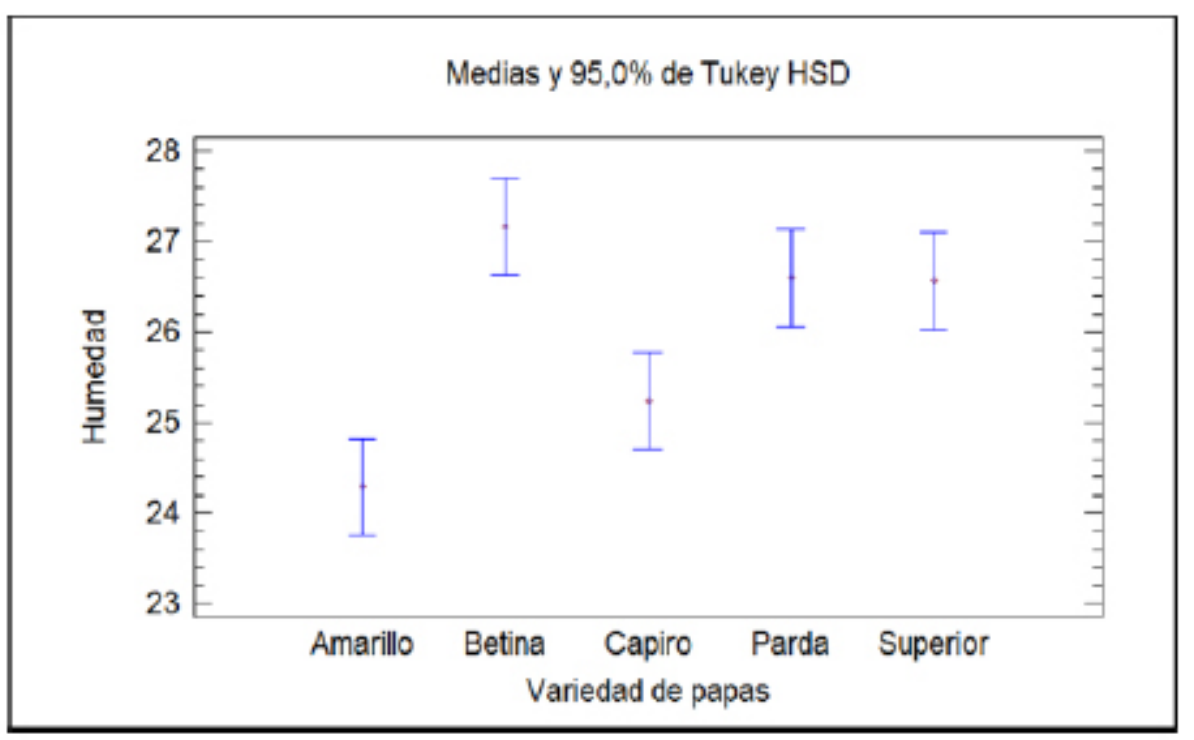

\section{Figura 1. Humedad en las variedades de papa.}

El porcentaje de humedad máximo establecido es del 17\%, los almidones AS, AIC, AP Y AB presentan un valor superior, por lo tanto, presentan implicaciones en la conservación y almacenamiento de este producto, además tienden a la formación de hongos y levaduras, que con lleva a la fermentación del mismo, aumentando de su acidez y la disminución del $\mathrm{pH}$. Por lo tanto, se determina que en el tiempo de secado del almidón fue insuficiente para cuadro variedades de almidón (AS, AIC, $\mathrm{AP}$ y $\mathrm{AB}$ ), por lo cual se recomienda incrementar el tiempo de secado, teniendo en cuenta las figuras de secado que establecen un tiempo de operación de aproximadamente 6 horas para obtener una humedad 17\% [13].

Porcentaje de Ceniza: Las medias de los diferentes almidones de papa no presentan una variación significativa, con un valor de P igual a $0.1175(\mathrm{p}>\alpha)$ y un nivel de confianza del $95 \%$, por lo tanto, se conformó un solo grupo.

Los almidones de la variedad de papa Ica-Capiro y parda, al presentar valores de ceniza mayores al 0,4\% [14], y menor que 3\% Codex Standard 176-1989, estos tipos de almidones son recomendados para ser utilizados en la industria puesto que el contenido de minerales en estos almidones, está relacionado con el contenido de fósforo, lo cual permite mejorar el proceso de hinchamiento de los gránulos de almidón, la estabilidad y claridad de la pasta, y reducción de la tasa de 
gelatinización [14].

Los almidones de papa superior, criolla y Betina, presentaron un valor inferior al límite superior establecido, por lo tanto, presentan inconvenientes en las propiedades funcionales de almidón como un aumento en la temperatura de gelatinización.

Porcentaje de Proteína: Este parámetro presentó variaciones significativas, con un valor de P igual a $0.0007(\mathrm{p}<\alpha)$, con un índice de confianza del $95 \%$, por lo tanto, se generaron dos grupos el primero está conformado por Almidón de la variedad de papa Betina y Parda, el segundo grupo integrado por Almidones de variedad de papa criolla, Ica-Capiro y superior ver Figura 2.

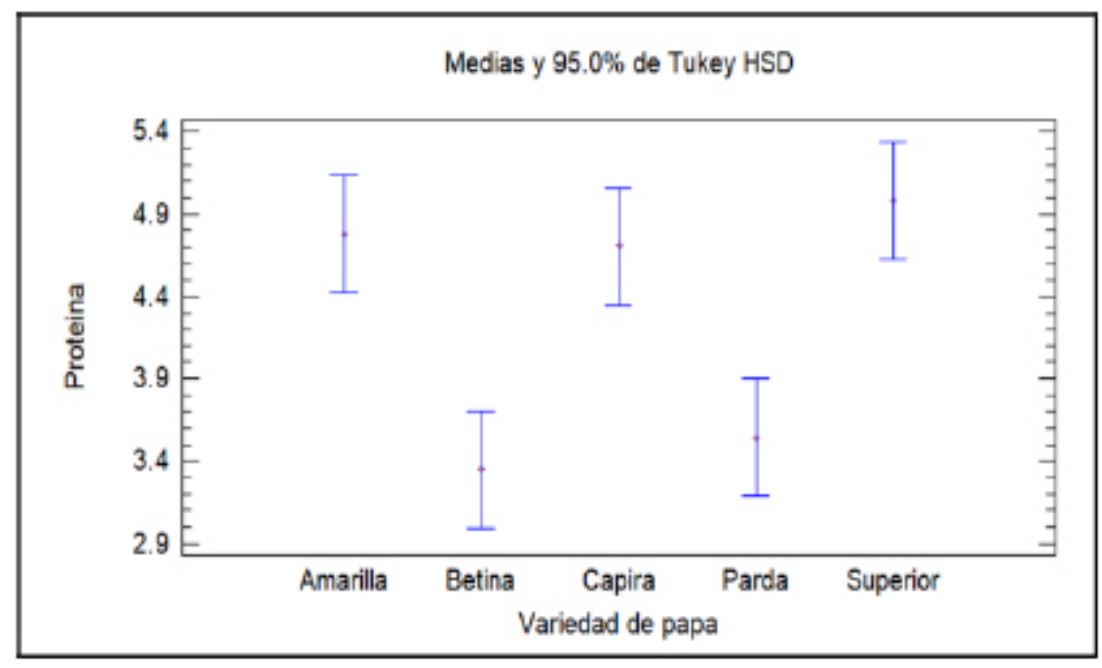

Figura 2. Proteína en las variedades de papa.

Los valores reportados por almidones de variedad de papa Betina y parda, se encuentran entre los rangos establecidos de $0,1-0,59 \%$ [15], con respecto a los almidones de variedad de papa criolla, Ica-Capiro y superior no se encuentra en el rango establecidos, por ende en la industria estos almidones al contener altos niveles de proteína afecta sus propiedades térmicas, su viscosidad y estabilidad, en el proceso de elaboración del bioplástico, además de aumentar su actividad espumante lo cual es indeseable, se recomienda en la etapa de decantación adicionar una solución de hidróxido de sodio $(0,02 \% \mathrm{p} / \mathrm{v})$,así las proteínas se solubilizan , permitiendo minimizar las alteraciones de sus propiedades funcionales [16], con el fin de permitir que estos almidones puedan ser utilizados en la industria. 
Porcentaje de Amilopectina y Amilosa: Los valores obtenidos con respecto a la amilosa y amilopectina, presentaron diferencias significativas, con un valor de $\mathrm{p}$ igual 0,0054 para la amilosa y un valor de p igual a 0,0054 para la amilopectina, con un nivel de confianza del $95 \%$.

Los resultados de amilosa y amilopectina reportaron la conformación de dos grupos, el primero de ellos integrado por almidón de variedad de papa superior, el segundo grupo por almidón de variedad de papa criolla y parda, con respecto a los almidones de variedad de papa Ica-Capiro y Betina, se relacionan e integran los grupos anteriormente definidos, ya que sus medias son similares.

Los diferentes almidones estudiados poseen buenas propiedades de formación de películas biodegradables y estabilidad química, excepto el almidón de variedad de papa superior; puesto que las otras clases de almidones presentan en su estructura el porcentaje de polisacáridos entre los rangos establecidos, con un porcentaje de amilosa entre 20 a $30 \%$ y el de amilopectina entre un $70 \%$ a $80 \%$ [17]. Estos almidones al presentar una relación adecuada entre amilosa/amilopectina proporciona a los bioplástico resistencia mecánica y flexibilidad, además se debe tener en cuenta que los almidones ricos en amilosa, poseen una mayor capacidad de moldeo y gelificación, en caso contrario el almidón se torna espeso, pero no gelifica [12].

Se recomienda en el caso de poseer un almidón rico en amilosa que genera un aumento en la resistencia del material, pero una disminución de la tensión, es necesario la adición de un plastificante como la glicerina o el glicerol, además de una adecuada formulación porque el exceso de estos componentes influye en la resistencia original del material.

Según lo anterior se deduce que los almidones de variedad de papa Betina y IcaCapiro, presentan una mejor relación y adecuada proporción entre amilosa y amilopectina, generando las mejores propiedades mecánicas a los bioplástico, puesto que las relaciones entre estos dos componentes proporcionan las mejores propiedades funcionales para el almidón.

Rendimiento de almidón: Los valores obtenidos con respecto al rendimiento de almidón, no están dentro de los rangos reportados por Subiabre [16], que obtuvo un rendimiento entre el 13 y 16\%. Mediante este método se identificó que existe un porcentaje de almidón sin extraer, en la etapa de filtración se hizo evidente la retención de almidón, como también en el proceso de pulverización y tamizado 
[16]. Las variedades de papa superior y criolla, presentaron un porcentaje de rendimiento mayor en comparación a las otras variedades.

\section{Características funcionales de las cinco variedades de papa.}

Los resultados de las pruebas funcionales realizadas a los diferentes almidones se presentan en la siguiente tabla 3.

\begin{tabular}{|c|c|c|c|c|}
\hline Tipo de Almidón & $\begin{array}{l}\text { Temperatura de } \\
\text { gelatinizacion }\left({ }^{\circ} \mathrm{C}\right)\end{array}$ & $\begin{array}{c}\% \text { Indice de } \\
\text { solubilidad (ISA) }\end{array}$ & $\begin{array}{c}\text { Indice de } \\
\text { absorbancia(IAA) }\end{array}$ & $\begin{array}{c}\text { \% Poder de } \\
\text { Hinchamiento (PH) }\end{array}$ \\
\hline Superior (AS) & $63^{2}$ & $5,11^{\mathrm{a}}$ & $3,692^{2}$ & $4,23^{2}$ \\
\hline Criolla (AC) & $65,25^{a}$ & $9,37^{\mathrm{a}}$ & $3,709^{2}$ & $4,55^{2}$ \\
\hline $\begin{array}{l}\text { ICA-Capiro } \\
\text { (AIC) }\end{array}$ & $63^{\mathrm{a}}$ & $8,91^{\mathrm{a}}$ & $3,024^{2}$ & $4,53^{2}$ \\
\hline Parda (AP) & $68,4^{2}$ & $1,52^{a}$ & $3,401^{2}$ & $3,63^{2}$ \\
\hline Betima $(A B)$ & $64,125^{2}$ & 1,875 & $3,130^{2}$ & $4,03^{2}$ \\
\hline
\end{tabular}

Tabla 3. Características funcionales de las variedades de papa

Temperatura de Gelatinización: Los valores obtenidos no presentaron diferencias significativas entre los almidones estudiados, con un valor de $\mathrm{P}$ igual a 0.7540 $(\mathrm{p}>\alpha)$ y un nivel de confianza del $95 \%$, por lo tanto, se conformó un solo grupo

Las temperaturas de gelatinización de los almidones estudiados están dentro del rango establecido entre 56 y $67^{\circ} \mathrm{C}$ [18], excepto el almidón de variedad de papa parda, por lo cual se deduce que los almidones estudiadas en comparación a los almidones extraídos de cereales estos espesan más, presentan mejores condiciones de viscosidad, resistencia, una temperatura de gelatinización menor debido a su mayor capacidad de absorción de agua mayor velocidad de hidratación y desintegración, debido a la presencia de grupos ésteres-fosfatos en las moléculas de amilopectina que posiblemente es una característica única para este tipo de almidón [19].

\section{Índice de absorción, solubilidad y poder de hinchamiento del almidón:}

El índice de absorción, solubilidad y poder de hinchamiento no presentaron diferencias significativas en los almidones estudiados, con un valor de $\mathrm{p}$ igual a $0.8064,0.554$ y 0.8936 respectivamente $(p>\alpha)$ y un nivel de confianza del $95 \%$, por 
lo tanto, se presenta un solo grupo en cada parámetro ver figura 3.
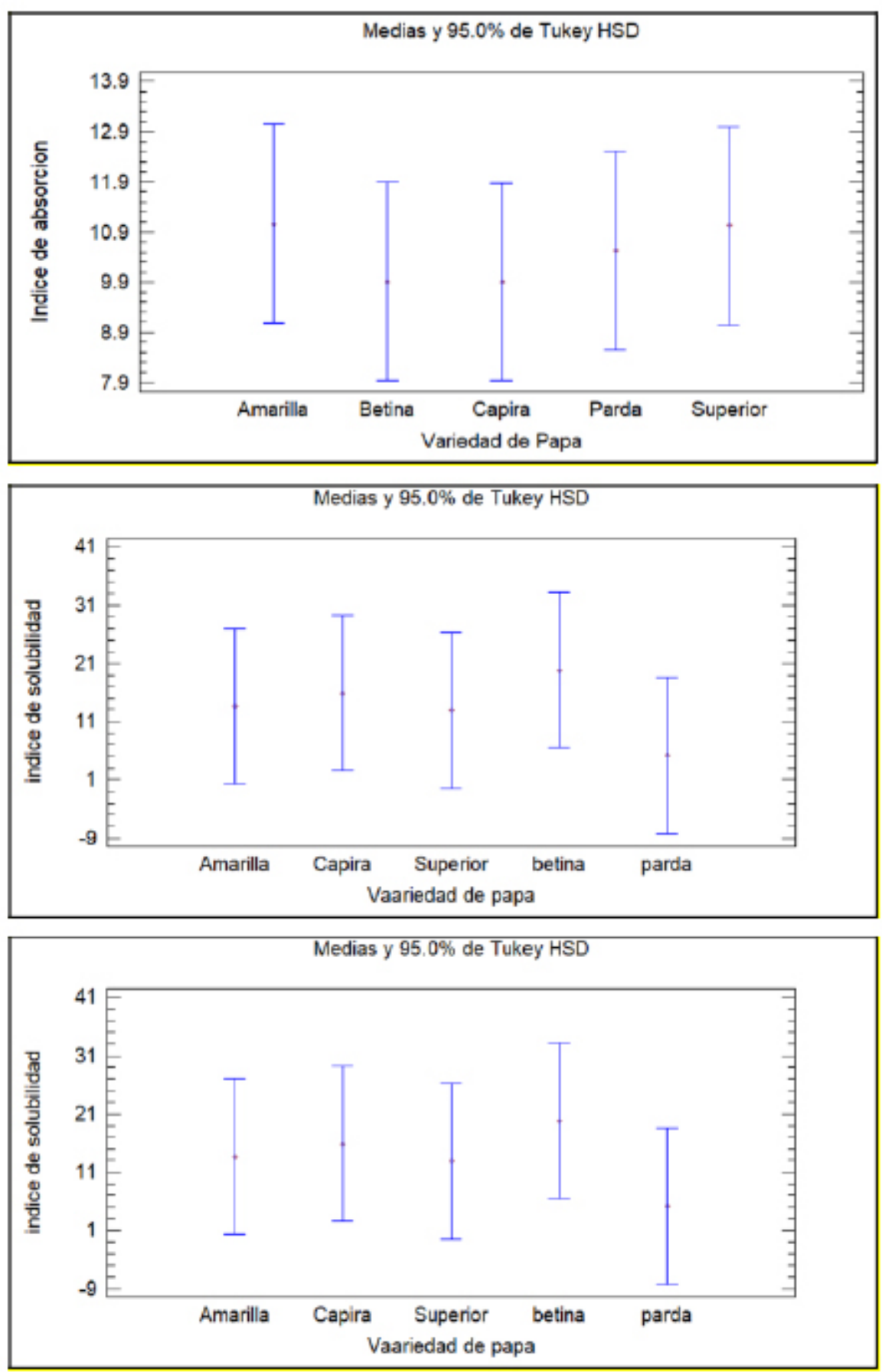

Figura 3. Índice de Absorción, índice de solubilidad y poder de hinchamiento en las variedades de papa.

Los almidones de papa generalmente presentan valores de IAA, PH Y ISA entre los rangos de 2,36-10,27 g gel/g muestra, 2.48-9,22 \%y 0,15-6,19\% respectivamente [20], en comparación a los almidones estudiados están dentro de estos límites. Por lo tanto, estos almidones son de buena calidad ya que poseen un alto nivel de absorción de agua, poder de hinchamiento y una baja solubilidad

Los almidones de papa estudiados, presentan una temperatura de gelatinización 
menor en comparación a otros almidones, esto genera un menor gasto energético en la elaboración de bioplástico, puesto que el proceso de plastificación se realiza en menor tiempo, además de presentar propiedades funcionales adecuadas que permiten que estos almidones realicen modificaciones químicas y físicas, puesto que por poseen grupos fosfatos adheridos a la estructura de la amilo pectina, por lo tanto es importante la presencia de un \% de ceniza en el almidón, ya que esta representa presencia de este mineral.

\section{Determinación de la materia prima para la elaboración de bioplástico:}

En la siguiente etapa se realizó la selección del almidón con la características fisicoquímicas y funcionales más adecuadas, para la elaboración del bioplástico, para lo cual se realizó una matriz de priorización con los siguientes parámetros de calificación, los resultados obtenidos se presentan en la tabla 4.

\begin{tabular}{|l|c|}
\hline Tipo de Almidón & Calificación \\
\hline Superior & 1,277 \\
\hline Criolla & 1,777 \\
\hline ICA-Capiro & 2,277 \\
\hline Parda & 1,777 \\
\hline Betina & 2,3325 \\
\hline
\end{tabular}

Tabla 4. Calificación obtenida para los almidones de papa cuarta categoría.

Según la tabla 3 el almidón con mayor calificación fue el almidón extraído de papa Betina, por lo tanto, se seleccionó este almidón para la elaboración del bioplástico, ya que presenta las características fisicoquímicas y funcionales adecuadas, para obtener un bioplástico con las características mecánicas idóneas, para un posible uso industrial.

\section{Características mecánicas de los bioplástico obtenidos.}

Las características mecánicas de los bioplástico obtenidos a partir del diseño experimental, se presentan en la tabla 5. 
Muestra \% Almidon Espesor(mm) Resistencia(MPa) \%Biodegradabilidad

\begin{tabular}{lllll}
1 & 3 & $0,1966^{\mathrm{a}}$ & $120,60^{\mathrm{a}}$ & 31,64 \\
2 & 6 & $0,293^{\mathrm{b}}$ & $120,25^{\mathrm{a}}$ & 60,4 \\
3 & 8 & $0,396^{\mathrm{c}}$ & $396,37^{\mathrm{b}}$ & 47,3 \\
\hline
\end{tabular}

Tabla 5. Características mecánicas de los bioplástico obtenidos.

Resistencia: En las diferentes muestras de bioplástico obtenidas se presentaron diferencias significativas en los valores de resistencia, con un valor de $\mathrm{p}$ igual a $0,0012(\mathrm{p}<\alpha)$, y un nivel de confianza del 95\% ver figura 4, por lo tanto, se presentó la formación de dos grupos, uno de ellos conformado por la muestra 1 y 2 , el segundo grupo por la muestra 3 .

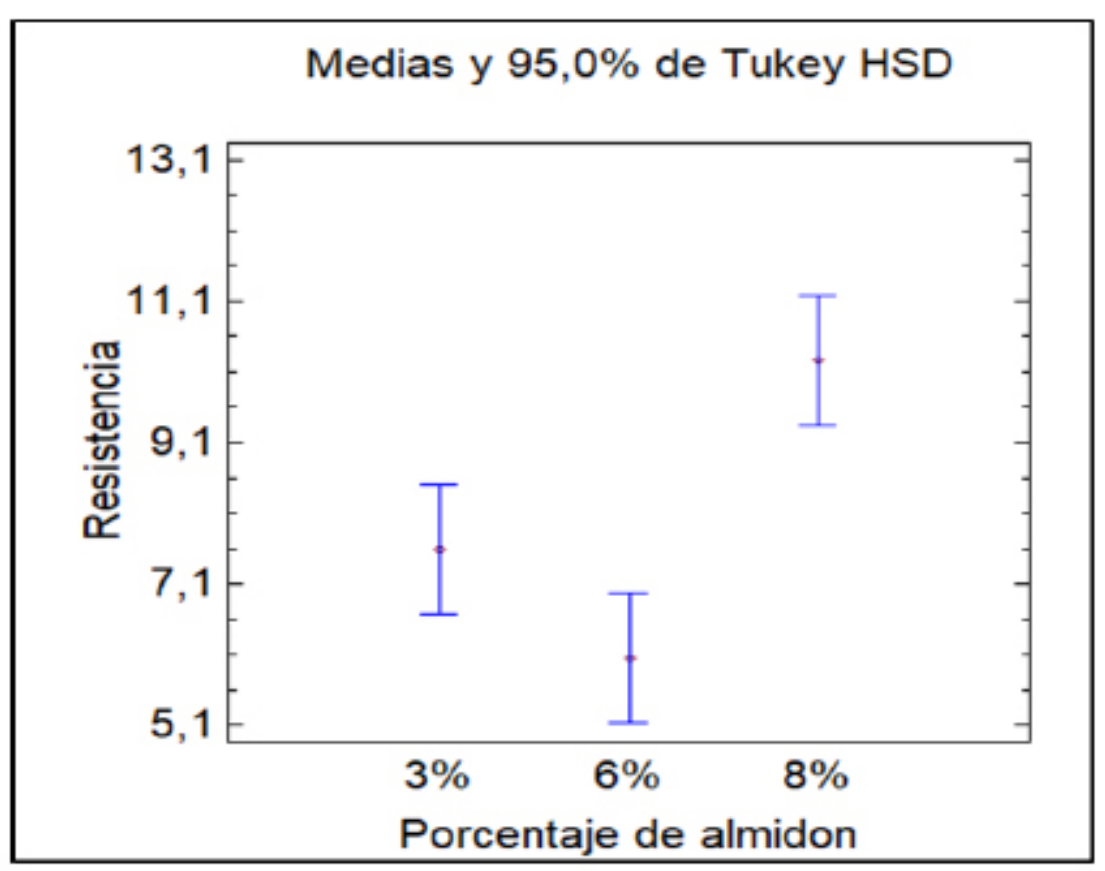

\section{Figura 4. Resistencia del bioplástico.}

La resistencia que determina la norma ASTM D-638 para plásticos está entre un rango, de 14-140 MPa, en comparación a los resultados obtenidos las muestras 1 y 2 , se encuentran dentro de este rango con un valor promedio de 120,42 MPa. Con respecto a la muestra número 3 presentó una resistencia mayor con un valor de 319,37 MPa, por lo tanto, el bioplástico obtenido posee una resistencia adecuada en comparación a los plásticos convencionales, por lo tanto, se deduce que puede tener posibles usos industriales [12]. 
Espesor: Las diferentes muestras obtenidas de bioplástico, se presentaron diferencias significativas en los valores de espesor, con un valor de p igual a 0,0001 $(\mathrm{p}<\alpha)$, y un nivel de confianza del $95 \%$, por lo tanto, se presentó la formación de tres grupos, uno de ellos conformado por muestra 1, el segundo grupo por muestra 2 y el tercer grupo por la muestra 3 ver figura 5.

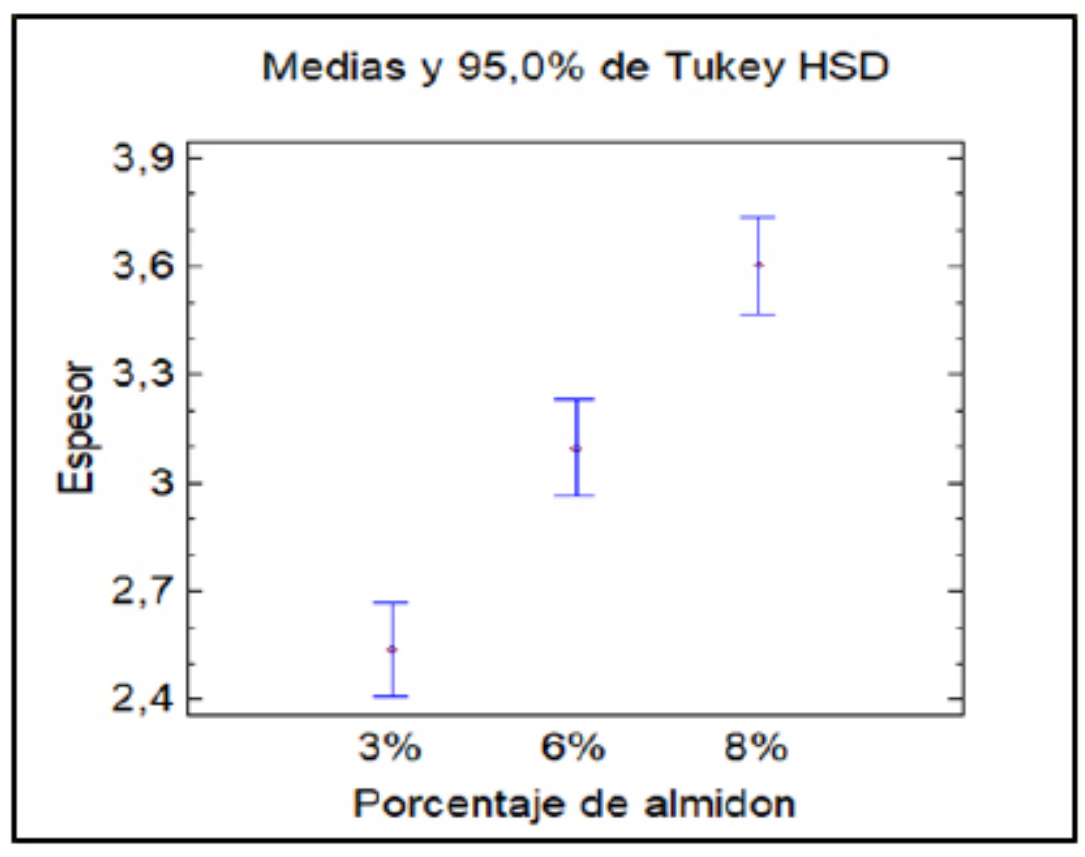

Figura 5. Espesor del bioplástico.

Kaur \& Singh [21], elaboraron películas de bioplástico a partir de almidón de papa, en este trabajo se realizó una variación de la concentración de almidón en un rango de 3-5 \% p/v, obteniendo resultados en el calibre de las películas de bioplástico en un rango entre $0,15-0,23 \mathrm{~mm}$, en comparación a los resultados obtenidos la muestra 1 y 2 están dentro de este rango, con respecto a la muestra 3 presentó un calibre superior con un valor de $0,39 \mathrm{~mm}$, se concluyó que la variación de la concentración de almidón es directamente proporcional al calibre, por lo tanto el aumento de la concentración de almidón en la solución genera un aumento en el espesor de las láminas de bioplástico.

\section{CONCLUSIONES}

El almidón de papa richie de la variedad Betina presenta mejores potencialidades para la elaboración de bioempaques.

Las cinco variedades de papa estudiadas, presentaron almidones con propiedades mecánicas y funcionales adecuadas para la elaboración de bioplástico, por lo tanto, los residuos de papa de cuarta categoría se pueden aprovechar para obtener un producto con valor agregado.

El bioplástico presento mayor resistencia, es firme y de buen aspecto cuando en la 
mezcla se adiciona mayor cantidad de agua y menor cantidad almidón.

En la elaboración del empaqué el plastificante más eficiente fue el agua destilada, pero en ausencia de glicerina el empaque obtenido presenta menor consistencia.

Se identifica que la temperatura ideal de plastificación para realizar la mezcla del bioplástico es de $60{ }^{\circ} \mathrm{C}$ y $70{ }^{\circ} \mathrm{C}$.

\section{REFERENCIAS}

[1] A. Rosales and J. Suazo, “Obtención De Biopolímero Plástico a partir del almidón de malanga (Colocasia esculenta), por el método de polimerización por condensación.," pp. 8-9, 2016.

[2] D. Cadena, "Plan De Negocios Para La Comercialización De Bolsas Plásticas Durables Reutilizables, Que Sustituyan Las Bolsas Plásticas En Los Almacenes De Grandes Superficies.," pp. 14-16, 2009.

[3] Agronet, Estadísticas agrícolas de área, producción y rendimiento de la papa en el departamento de Nariño.

[4] Fonseca, L. (2015). Programa de apoyo agrícola y agroindustrial vicepresidencia de fortalecimiento empresarial cámara de comercio, 30.

[5] N. Montoya, I. Pino, and H. Correa, "Evaluación de la suplementación con papa (Solanum tuberosum) durante la lactancia en vacas Holstein," Rev. Colomb. Ciencias Pecu., 2004.

[6] J. Gutiérrez, "Estudio de la interacción de los biopolímeros caseína y almidón por el proceso de extrusión”. 2004.

[7] J. Aristizabal and T. Sánchez, "Guía técnica para producción y análisis de almidón de yuca," pp. 16-18, 2007.

[8] Hernández, M., Marilyn, T., \& Juan, G. (2008). Caracterización fisicoquímica de almidones de tubérculos cultivados en Yucatán, México, 2008, 718-726.

[9] Lascano, A., \& Sandoval, G. influencia de la sustitución parcial de la harina de trigo por la harina de quinua y papa en las propiedades termodinámicas y de panificación de masas, 199-207, 2012.

[10] FAO. Guía técnica para producción y análisis de almidón de yuca. Boletín de Servicios Agrícolas de La FAO, 83-84.2007. 
[11] M. Charro, "obtención de plástico biodegradable a partir de almidón de patata" pp. 23-25, 2015.

[12] A. García, "Obtención de un Biopolímero biodegradable a Partir de Almidón de maíz". 2015, pp. 1-52.

[13] C. López., S. Pérez, "Extracción de almidón a partir de variedades de papas cultivadas en Nicaragua". 2014.

[14] G. Vargas., P. Martínez., C. Velezmoro. "propiedades funcionales del almidon de papa y su modificación química por acetilación”. 2016.

[15] O. Pardo., Castañeda., C. Ortiz. "Caracterización estructural y térmicas de almidones provenientes de diferentes variedades de papa”. 2013.

[16] D. Subiabre. "Ensayo Comparativo de Dos Metodologías de Extracción de Almidón de Papa usando Muestras de Diez Variedades Nativas de Chiloé y dos Variedades Comerciales", 13-14. 2010.

[17] M. Oñate., "Relación entre algunas propiedades fisicoquímicas y térmicas de gelatinización y retrogradación en almidón de papa nativa de Chiloé”. 2012.

[18] C. Velez. “Análisis Físico-Químico y Morfológico de Almidones de Ñame, Yuca y Papa y Determinación de la Viscosidad de las Pastas”. 2008.

[19] R. Espinoza. "Relación entre el contenido de fósforo y algunas propiedades térmicas y reológicas en almidón de papa nativa de Chiloé"

[20] L. Ramirez., L. Zarate., N. Santamaría. “caracterización de almidón nativo extraído de clones promisorios de papa criolla (solanum phureja) para su aplicación en un derivado cárnico". 2013

[21] L. Kaur., J. Singh. “Novel Applications of Potatoes". 2004

Acosta, $J^{1}$, Gomajoa, H1, Benavides, $Y^{2}$, Charfuelan, $A^{2}$, Valenzuela, $F^{2}$ ${ }^{1}$ Grupo de Investigación GIIDOP. Universidad Mariana. Ingeniería de Procesos. Docente Investigador. San Juan de Pasto. Nariño. Colombia

${ }^{2}$ Grupo de investigación GIIDOP. Universidad Mariana. Ingeniería de Procesos. Estudiante Investigador. San Juan de Pasto. Nariño. Colombia Autor de correspondencia: Charfuelan Andrés Hernando. E.mail. 